\section{CHILDHOOD OBESITY}

\section{A LONG-TERM STUDY OF HEIGHT AND} WEIGHT

BY

JUNE K. LLOYD, M.B., M.R.C.P., D.P.H.

O. H. WOLFF, M.A., M.D., M.R.C.P., D.C.H.

AND

\section{W. S. WHELEN,* M.D.}

From the University Department of Paediatrics and Child Health and the Children's Hospital, Birmingham

There are only a few studies of the natural history of childhood obesity. Mullins (1958) found about one-third of adults attending his out-patient department to be overweight, and in one-third of these the obesity dated from childhood. The only long-term prospective study of childhood obesity appears to be that of Haase and Hosenfeld (1956). It was based on 335 overweight children first examined between 1936 and 1940. Fifty of these patients were re-examined after the war, when the majority were between 20 and 36 years of age. Four-fifths of the patients were still grossly overweight and only 11 were less than $20 \%$ overweight. Whereas at the first examination no patient had been more than $80 \%$ overweight, at the follow-up examination three were more than $80 \%$ overweight. The prognosis tended to be worse for the girls than for the boys.

We present the results of a nine-year prospective study of the weights and heights of a group of 98 overweight children.

\section{Patients and Methods}

In 1950 a clinic for the treatment of overweight children was started at the Children's Hospital, Birmingham. Our observations are based on the first 98 children to attend this clinic with simple obesity.

The patients were re-examined in 1951, 1956, and 1959. The findings in 1950 and 1951 have already been reported (Wolff, 1955). During this first period treatment consisted of a 1,000-calorie diet and amphetamine sulphate, and most of the children attended the clinic regularly. After 1951 only a few attended regularly. Table I gives the number of patients followed up on

TABLE I.-The Follow-up

\begin{tabular}{|c|c|c|c|c|c|}
\hline \multirow{2}{*}{ Year } & \multicolumn{2}{|r|}{ Boys } & \multicolumn{2}{|r|}{ Girls } & \multirow{2}{*}{$\begin{array}{l}\text { Total } \\
\text { No. }\end{array}$} \\
\hline & No. & Mean Age and Range & No. & Mean Age and Range & \\
\hline 1950 & 39 & 9 yrs 4 mths (1 yr 4 & 59 & 9 yrs (1 yr 10 mths- & 98 \\
\hline 1951 & 33 & 10 yrs 9 mths (3-15 & 49 & 10 yrs 3 mths (4- & 82 \\
\hline 1956 & 33 & 14 yrs 6 mths (7- & 52 & $\begin{array}{c}14 \text { yrs } 8 \text { mths (7- } \\
20 \text { yrs) }\end{array}$ & 85 \\
\hline 1959 & 26 & 18 yrs 2 mths (10- & 41 & $\begin{array}{l}17 \text { yrs } 7 \text { mths (11- } \\
23 \text { yrs) }\end{array}$ & 67 \\
\hline
\end{tabular}

each occasion and the mean age and range of the group. A total of 89 of the original 98 children were re-examined in 1956 and/or 1959 . Of the nine patients whom we were unable to contact in 1956 or 1959 , six had already been lost sight of in 1951 .

Heights.-The height was measured with a stationary measure having a sliding headarm except when the examination tock place in the patient's home, when a flexible metal tape-measure was used. The height was

*Present address, 360 Queens Avenue, London, Ontario, Canada. recorded to the nearest quarter-inch with the patient erect and barefoot.

Weights.-The weight was taken with platform scales of the spring-balance type and recorded in pounds. At the first two examinations the children were weighed without clothes except pants. At the last two examinations weights were taken in indoor clothes without jacket and shoes. Correction for the weight of the clothes was made from Widdowson's (1947) table.

Eleven of the 85 patients contacted in 1956 and 6 of the 67 contacted in 1959 were not seen by us but recorded their heights and weights themselves.

\section{Standards Used}

In the previous study (Wolff, 1955) we used the standards for weight and height of Engelbach (1932), which up to the age of $13 \frac{1}{2}$ are in close agreement with recent standards for English children (Daley, 1950). Engelbach's height-for-age data for children up to $13 \frac{1}{2}$ years also agree closely with the most recent standards for English children by Tanner (1958). But for children over the age of $13 \frac{1}{2}$ Engelbach's standards no longer apply to post-war English children, who are now significantly taller than the pre-war generation. In our study of the ultimate height reached by obese children we have therefore used Tanner's data as a standard. These probably represent the most reliable data available for the age-group 17-18, though Tanner himself points out that they are not based on measurements, but are arrived at by extrapolation. Tanner's data as regards boys are in close agreement with those obtained by Morant (1952) for apprentices in the Royal Air Force. To confirm the suitability for our purposes of Tanner's standard for girls we obtained the heights of 105 English nurses aged 17-19 years inclusive in training at the Birmingham Children's Hospital. Their mean height was 64.3 in. $(163.3 \mathrm{~cm}$.) (standard deviation : 2.33 in. $(5.9 \mathrm{~cm}$.) ). This figure is again in fair agreement with Tanner's standard.

When studying the prognosis of the obesity, we have estimated overweight by comparing the actual weight with the standard for the patient's sex and height and have expressed the result as a percentage. In these calculations Engelbach's weight for height tables were used. The use of Engelbach's standard in this connexion is justified by the fact that, despite the welldocumented secular trend for the growth spurt to occur earlier (Tanner, 1955), the relationship between weight and height has remained relatively constant over the years.

\section{Results \\ Ultimate Height}

Figs. 1 ard 2 show the height of the patients at the first and last $\because:$ aminations. For clarity and convenience we have ex, led the 13 children who were under 5 years at the $f$. I examination and the 7 who were under 14 at the last . mination. At the first examination the patients had eit. not yet entered puberty or were passing through the y2: $: s$ of puberty. It has already been shown (Wolff, 1955) that at this time the children were significantly taller than the standard. At the last examination, nine years later, most of the patients had completed puberty and had reached an age when growth in height has usually ceased (Clements, 1954). Their height was now below that expected for individuals of the same age and sex. The 25 girls who were over $17 \frac{1}{2}$ years of age and in whom growth in height had therefore ceased completely, or almost so, had a mean height 


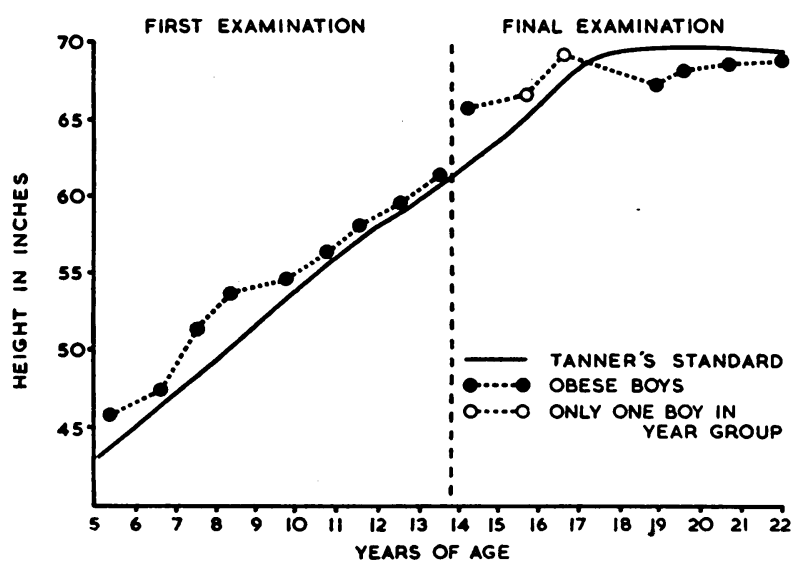

Fig. 1. - Height in relation to age for the boys.

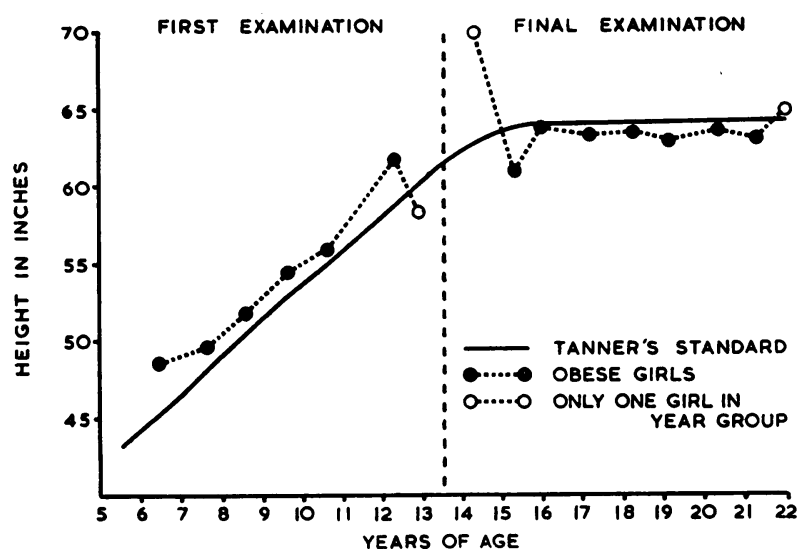

Fig. 2.-Height in relation to age for the girls.
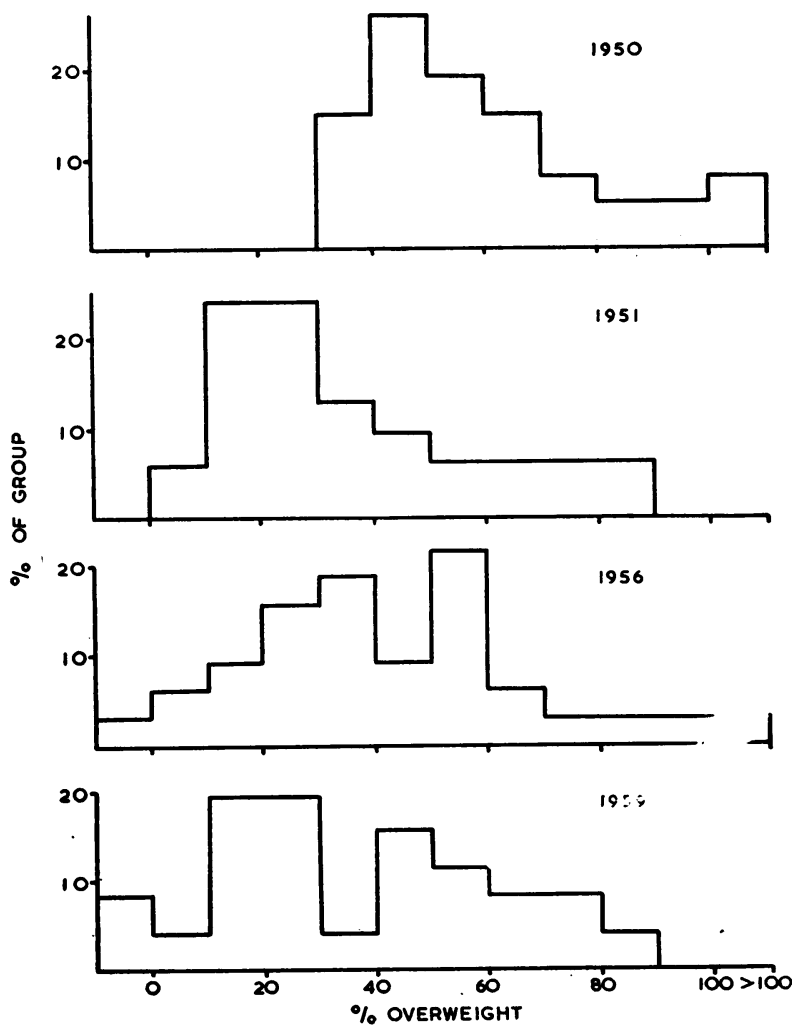

FIG. 3.-Percentage overweight for the boys. of 63.17 in. $(160.4 \mathrm{~cm}$.) (standard deviation : 2.11 in. $(5.36 \mathrm{~cm})$.$) compared with Tanner's standard of 64 \mathrm{in}$. $(162.5 \mathrm{~cm}$.) $(\mathrm{t}=1.98, \mathrm{P}=0.05)$. The 19 boys who were over 18 years and in whom growth had therefore ceased completely, or almost so, had a mean height of 68.16 in. $(173.1 \mathrm{~cm}$.) (standard deviation: 2.98 in. (7.6 $\mathrm{cm}$.) ) compared with Tanner's standard of 69 in. (175.2 $\mathrm{cm}$.) $(\mathrm{t}=1.23, \mathrm{P}=0.2)$. The mean under-height of the two sexes, taken together, is 0.835 in. $(2.22 \mathrm{~cm}$.) (standard deviation : 2.49 in. $(6.3 \mathrm{~cm})$.$) , and this differs significantly$ from Tanner's standard $(\mathrm{t}=2.22, \mathrm{P}=0.05-0.02)$.

Further analysis of our data suggests that the patients who at the first examination had been much above the expected height tended to reach an ultimate height close to the standard, whereas the patients who at the first examination had been of standard or even below standard height tended to have an ultimate height below the standard.

\section{Prognosis of the Obesity}

Figs. 3 and 4 show the percentage overweight for height in 1950, 1951, 1956, and 1959 for boys and girls respectively. Table II gives the mean overweight and standard deviation.
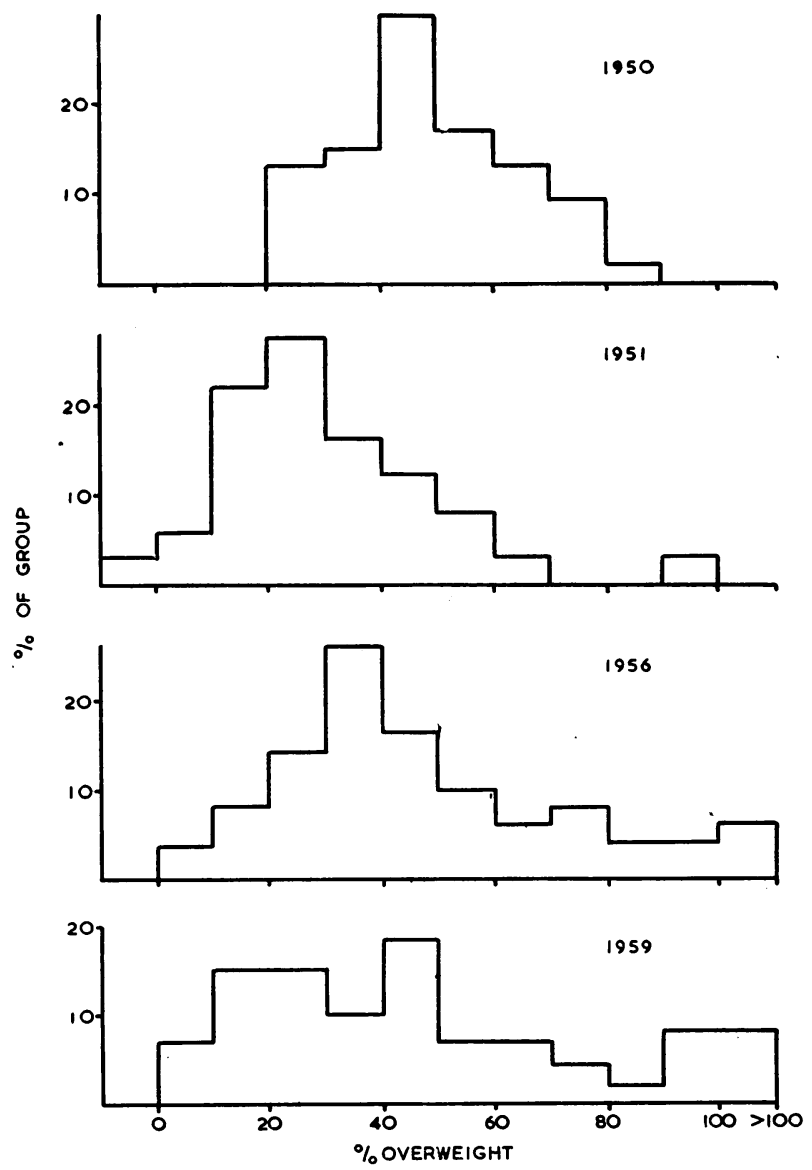

Fig. 4.-Percentage overweight for the girls.

\begin{tabular}{c|c|c|c|c}
\multicolumn{3}{c}{ TABLE II.-Prognosis of Obesity } \\
\hline \multirow{3}{*}{ Year } & \multicolumn{2}{|c}{ Boys } & \multicolumn{2}{c}{ Gir1s } \\
\cline { 2 - 6 } & $\begin{array}{c}\text { Mean } \\
\text { Overweight (\%) }\end{array}$ & $\begin{array}{c}\text { Standard } \\
\text { Deviation }\end{array}$ & $\begin{array}{c}\text { Mean } \\
\text { Overweight(\%) }\end{array}$ & $\begin{array}{c}\text { Standard } \\
\text { Deviation }\end{array}$ \\
\hline 1950 & 63 & 29.8 & 58 & 15.6 \\
1951 & 35 & 23.5 & 30 & 17.8 \\
1956 & 44 & 27.7 & 50 & 30.4 \\
1959 & 35 & 24.2 & 48 & 33.5 \\
\hline
\end{tabular}


During 1950 and 1951, when the patients received intensive treatment, a highly significant reduction in mean overweight occurred in both sexes (boys : $t=4.51$, $P=0.001$; girls : $t=8.62, P=0.001$ ). However, between 1951 and 1956 a relapse occurred which was highly significant in the girls $(t=3.30, P=0.001)$, but failed to reach statistical significance in the boys $(t=1.38$, $\mathbf{P}=0.1-0.2$ ). Between 1956 and 1959 no significant change took place in either sex, though in the boys there was a tendency to improvement.

Table III gives the mean overweight at the last examination for boys over 18 and girls over $17 \frac{1}{2}$, when growth had presumably ceased. The group is divided into two : those over and those under 20 years of age. The older age-group was on average more overweight than the younger, and the difference between the two groups, taking the sexes together, is significant $(\mathrm{t}=2.0, \mathrm{P}=0.05)$.

TABLE III.-Overweight of Girls Over $17 \frac{1}{2}$ Years and Boys Over 18 Years

\begin{tabular}{|c|c|c|c|c|}
\hline- & & No. & Mean Overweight $\%$ & S.D. \\
\hline Boys $\left\{\begin{array}{l}18-19 \text { years } \\
20 \text { years and ove }\end{array}\right.$ & $\begin{array}{l}. \\
\cdots\end{array}$ & $\begin{array}{r}13 \\
7\end{array}$ & $\begin{array}{l}33 \cdot 5 \\
41 \cdot 6\end{array}$ & $\begin{array}{l}19 \cdot 87 \\
23.0\end{array}$ \\
\hline Girls $\left\{\begin{array}{l}17 \frac{1}{2}-19 \text { years } \ldots \\
20 \text { years and over }\end{array}\right.$ & $\begin{array}{l}\cdots \\
\cdots\end{array}$ & $\begin{array}{l}14 \\
10\end{array}$ & $\begin{array}{l}41 \cdot 0 \\
65 \cdot 8\end{array}$ & $\begin{array}{l}28 \cdot 65 \\
35 \cdot 8\end{array}$ \\
\hline
\end{tabular}

Comparison of the weights at the last examination of the patients who at the first examination had been least overweight $(30-39 \%)$ with the weights of those who had been most overweight (over $80 \%$ ) shows that a highly significant difference $(t=2.66, P=0.02-0.01)$ had persisted (Table IV).

TABLE IV.-Relationship Between Overweight at First and Last Examinations

\begin{tabular}{|c|c|c|c|}
\hline & & \multicolumn{2}{|c|}{ Overweight at 1st Examination } \\
\hline & & $30-39 \%$ & Over $80 \%$ \\
\hline $\begin{array}{l}\text { Number } \\
\text { Mean overweight at last examination } \\
\text { Standard deviation } \ldots\end{array}$ & $\begin{array}{l}\cdots \\
\cdots \\
\cdots\end{array}$ & $\begin{array}{l}11 \\
44 \\
24 \cdot 7\end{array}$ & $\begin{array}{l}13 \\
78 \\
37 \cdot 6\end{array}$ \\
\hline
\end{tabular}

Of the 13 children who were grossly overweight at the first examination, only one had returned to near normal weight. This was a girl who at the beginning of treatment was 4 years old and $98 \%$ above expected weight. Fifteen months later she was only $26 \%$ overweight, and at the final examination, when $12 \frac{1}{2}$ years old, she was $10 \%$ overweight. The remaining 12 were still grossly overweight (range, 47-153\%). Of the 11 children who at the first examination were leasi overweight, only 3 were less than $20 \%$ overweight at the final examination; the remaining 8 were more than $45 \%$ overweight.

A few findings of negative prognostic significance can be summarized: the rate at which the patients lost weight during the period of intensive therapy between the first and second examinations bore no relationship to the degree of overweight at the final examination. In fact, the nine children who during the initial period lost weight at a monthly rate of more than $4 \%$ of their expected weight were at the final examination on average $78 \%$ above expected weight, and only one of them had returned to near normal weight.

The mean overweight at the final examination of the patients whose weight after intensive treatment had returned to near normal-that is, less than $20 \%$ overweight-did not differ significantly from that of the children whose weight had responded less satisfactorily to treatment. In fact, of the 20 children who at the second examination were less than $20 \%$ overweight, only 4 were less than $20 \%$ overweight at the final examination. In other words, in four-fifths the condition had relapsed.

Age at the first examination had no bearing on the prognosis.

\section{Discussion}

The finding that obesity in childhood is likely to persist into adult life is in agreement with that of Haase and Hosenfeld (1956), and, like these authors, we find that the outlook may be a little better for boys than for girls. The influence of overweight on the morbidity and mortality of adults is well recognized, and there is reason to believe that weight reduction brings improved health and longevity (Marks, 1960). A better understanding of the natural history of obesity thus leads to a greater emphasis on the treatment of the condition in childhood. In this connexion we wish to stress the great importance, after initial weight reduction, of longcontinued supervision to prevent relapse. Our experience with the grossly overweight child-that is, more than $50-60 \%$ above the expected weight-suggests that hospitalization may often be necessary initially to achieve satisfactory weight reduction.

Previously (Wolff, 1955) it was shown that obese boys and girls tend to be above average height compared with children of all social classes, but that their height does not differ significantly from children of the upper social classes. It was also shown that they enter puberty about one year earlier than average. One reason for the present study was to determine the ultimate height reached by the overweight child. As Tanner (1955) states, final size and the speed with which it is attained are not necessarily related. Studying boys, he concludes that there is a strict relationship between adult height and maturity group, the latest maturers being the tallest, and Stone and Barker (1937) found that later-maturing girls are somewhat taller than average. It is then not surprising that the ultimate height of the obese child, who is known to mature early, is shorter than average, even though until puberty he was taller.

\section{Summary}

In a nine-year prospective study of a group of 98 children with simple obesity their ultimate height was found to be significantly below standard height, even though before the onset of puberty their height had been above the standard.

There was a strong tendency for the obesity to recur after initial weight reduction and then to persist into young adult life. At the last examination only onequarter of the group had achieved normal or near normal weight (less than $20 \%$ overweight) and among the girls the proportion of grossly overweight patients (above $80 \%$ overweight) was greater than at the first examination. Energetic treatment of obesity in childhood followed by prolonged supervision to prevent relapse is important in the prevention of obesity in the adult with its well-recognized influence on morbidity and mortality.

We are grateful to Miss M. Woods, our matron, for allowing us access to the height and weight records of the nurses. 


\section{REFERENCES}

Clements, E. M. B. (1954). Arch. Dis. Childh., 29, 147.

Daley, A. (1950). L.C.C. Report on the Heights and Weights of School Pupils in the County of London in 1949. L.C.C., London.

Engelbach, W. (1932). Endocrine Medicine, 1. 304. Thomas, Springfield, Ill.

Haase, K.-E., and Hosenfeld, H. (1956). Z. Kinderheilk., 78, 1.

Marks, H. H. (1960). Bull. N.Y. Acad. Med., 36, 296.

Morant, G. M. (1952). Air Ministry, Flying Personnel Research Committee, Report No. $711 \mathrm{f}$ (unpublished).

Mullins, A. G. (1958). Arch. Dis. Childh., 33, 307.

Stone, C. P., and Barker, R. G. (1937). Hum. Biol., 9, 1.

Tanner, J." M. (1955). Growth at Adolescence." Blackwell, Oxford.

(1958). In Modern Trends in Paediatrics, edited by A.

Holzel and J. P. M. Tizard, p. 325. Butterworth, London.

Widdowson, E. M. (1947). Spec. Rep. Ser. med. Res. Coun. (Lond.), No. 257, p. 10 .

Wolft, O. H. (1955). Quart. J. Med., 24, 109.

\section{TUBERCULOSIS IN SOHO}

BY

\section{PETER A. EMERSON, M.A., M.D., M.R.C.P.}

GILLIAN BEATH, M.A., A.M.I.A.

Westminster Hospital Chest Clinic, London

AND

\section{JOHN G. TOMKINS, M.B., B.Ch., B.Sc.}

South-West London Mass $X$-ray Service

Of the 3,105 catering establishments in the City of Westminster over 400 are concentrated in Soho. Tinker (1959) suggested that workers in the catering trade in this area have a particularly high incidence of pulmonary tuberculosis. The present survey was made to try to find out the true position and to answer certain questions. For instance, is tuberculosis usually contracted before or after joining the trade? If before, is it because catering attracts workers whom tuberculosis has incapacitated for other types of work, or is it, in the case of workers from abroad, because they already have the disease when they arrive in Britain ? If after, is it because previously uninfected workers get their primary infection after entering the crowded working conditions of the trade, or is it simply that those who have already had their primary infection break down as a result of adverse working or living conditions ?

\section{Method}

The area chosen for the inquiry was the electoral ward of Soho, which covers about $1 / 7$ square mile $(0.37$ sq. $\mathrm{km}$.) in the City of Westminster. The names of some 400 catering establishments were provided by the Public Health Department and 240 were included in the survey. There were 47 public-houses and 193 restaurants, cafés, and coffee-bars. It was not administratively possible to include the clubs, staff canteens, and theatre bars which made up the total figure.

A personal letter was written to each proprietor, manager, or licensee, explaining the purpose of the survey and asking him to supply the names of his staff so that each individual could be sent an explanatory letter and an appointment for an $x$-ray examination. Replies to these letters were received from 105 establishments; 96 gave the names of their staff and 9 gave numbers only. One of us (G. B.) visited the 135 employers $(56 \%)$ who did not reply, and on this approach a further 99 gave the names of their staff and
34 gave numbers, thus leaving only two establishments from which no information could be obtained. In this way the total sample was estimated to be 4,733 workers.

Arrangements were made with the South-West London Mass $X$-ray Service for one of their mobile units to make 12 visits to various sites in Soho between January and June, 1960, and for their static unit to make a four-day visit to one large establishment which employed approximately 1,800 people. It was not possible to send each of these 1,800 workers an individual letter, but the management publicized the visit and encouraged their employees to attend during working hours ; 930 (52\%) of the 1,800 were interviewed and $x$-rayed.

Each of the sites chosen for the mobile unit was as near to as many restaurants as possible. About four days before each visit of the unit an explanatory letter was sent to each person in the appropriate restaurants telling them the time and place for their $x$-ray examination. In this way personal letters were sent to 2,933 workers and $1,319(45 \%)$ kept the appointment to be interviewed and $x$-rayed. Those who failed to attend were sent another appointment and asked to state whether they were already attending a chest clinic or hospital. Information and $x$-ray films were obtained for a further $362(12 \%)$.

Thus, of the 4,733 workers approached in various ways, $2,611(55 \%)$ responded. Before being $x$-rayed each person was interviewed and helped to complete a questionary answering the following questions: Age ? Sex ? Address? Occupation? Place of work? In which country did you spend your childhood? How many years have you spent in the catering trade? How long have you been at this café/restaurant/publichouse? How long have you been in Great Britain?

Those workers whose miniature chest radiographs were normal were so informed and those with abnormal films were recalled for further radiological and clinical assessment at Westminster Hospital Chest Clinic. After any necessary investigations the workers with radiographic evidence of pulmonary tuberculosis were classified as follows:

1. Active pulmonary tuberculosis requiring treatment with antituberculous drugs: (a) sputum negative for tubercle bacilli, $(b)$ sputum positive for tubercle bacilli.

2. Pulmonary tuberculosis not requiring active treatment but requiring observation at clinic.

3. Healed pulmonary tuberculosis not requiring observation and therefore discharged from further attendance.

In the patients who showed evidence of pulmonary tuberculosis an assessment was also made of the duration of the disease, with particular reference to the time of joining the catering trade and, in the case of immigrants, the time of arrival in Great Britain. This assessment was made on the clinical history, the radiographic appearances, and the history of previous radiographic examinations.

Of the 2,611 workers examined, 86 showed radiological evidence of past or present tuberculosis. The 86 cases were divided into three groups. In the first or " active" group there were 21 patients suffering from active tuberculosis requiring treatment with antituberculous drugs: sputum examinations for tubercle bacilli were positive in 6 and negative in 15 . In the second or "observed" group there were 32 patients with tuberculosis requiring clinic observation only; two of these patients were already attending a chest clinic elsewhere. 